\title{
Estimation of the fracture toughness of tungsten fibre-reinforced tungsten composites
}

\author{
H. Gietl ${ }^{\mathrm{a}, \mathrm{b}}$, S. Olbrich ${ }^{\mathrm{a}}$, J. Riesch ${ }^{\mathrm{a}}$, G. Holzner ${ }^{\mathrm{a}, \mathrm{b}}$, T. Höschen ${ }^{\mathrm{a}}$, J.W. Coenen ${ }^{\mathrm{c}, \mathrm{d}}$, R. Neu ${ }^{\mathrm{a}, \mathrm{b}}$ \\ ${ }^{a}$ Max-Planck-Institut für Plasmaphysik, Boltzmannstrasse 2, 85748 Garching, Germany \\ ${ }^{b}$ Technische Universität München, Boltzmannstrasse 15, 85748 Garching, Germany \\ ${ }^{c}$ Forschungszentrum Jülich GmbH, Institut für Energie und Klimaforschung, Partner of the Trilateral Euregio Cluster (TEC), 52425 Juelich, Germany \\ ${ }^{d}$ Department of engineering physics, University of Wisconsin Madison, WI 53706 Madison, USA
}

\begin{abstract}
Tungsten fibre-reinforced tungsten composites $\left(\mathrm{W}_{\mathrm{f}} / \mathrm{W}\right)$ have been developed to overcome the inherent brittleness of tungsten, which is a promising candidate for the plasma-facing material in a future fusion power plant. As the development of $\mathrm{W}_{\mathrm{f}} / \mathrm{W}$ evolves, the fracture toughness of the composite is in the focus of interest for further component design. In this contribution fracture mechanical tests on two different types of chemical vapour deposited (CVD) $\mathrm{W}_{\mathrm{f}} / \mathrm{W}$ are presented. Three-point bending tests according to ASTM E399 as a standard method for brittle materials were used to get a first estimation of the toughness. A provisional fracture toughness value of up to $241 \mathrm{MPa} \mathrm{m}^{1 / 2}$ was calculated for the as-fabricated and of up to $20.5 \mathrm{MPa}^{1 / 2}$ for a heat-treated and thus embrittled state. As the material does not show a brittle fracture in the as-fabricated state, the J-Integral approach based on the ASTM E1820 was additionally applied for this state. A maximum value of the J-integral of $7.5 \mathrm{~kJ} / \mathrm{m}^{2}\left(57.6 \mathrm{MPa} \mathrm{m}^{1 / 2}\right) \mathrm{was}$ determined. A detailed post mortem investigations was used to obtain the active mechanisms.
\end{abstract}

Keywords: tungsten, tungsten fibre, fibre-reinforced composite, metal matrix composite, fracture toughness

\section{Introduction}

The ideal material for highly loaded areas in a future fu- 3 sion device needs to combine properties such as low sputter ${ }_{34}$ yield, high melting point, high thermal conductivity and mod- 35 erate activation [3]. Tungsten (W), as a promising candidate 36 for such structures, in addition also features high strength and ${ }_{37}$ creep resistance at elevated temperatures. However, the inher- 38 ent brittleness below the ductile-to-brittle transition temperature (DBTT) $[4,5]$ and the embrittlement during operation, 40 e.g. by overheating [6] and/or neutron irradiation [7, 8] are the ${ }_{41}$ main drawbacks for the use of pure W. To overcome this lim- 42 itation, tungsten fibre-reinforced tungsten composites $\left(\mathrm{W}_{\mathrm{f}} / \mathrm{W}\right)$ have been developed. Besides short fibre reinforced $\mathrm{W}_{f} / \mathrm{W}$ produced with a powder metallurgical process $[9,10]$, a promising 43 production route for $\mathrm{W}_{f} / \mathrm{W}$ reinforced with continuous fibres is 44 a layered chemical vapour deposition (CVD) process [11, 12]. The composites utilise extrinsic mechanisms to improve the 45 toughness [13, 14], similar to ceramic fibre-reinforced ceram- 46 ics [15]. These mechanisms work for as-fabricated conditions 47 of $\mathrm{W}_{\mathrm{f}} / \mathrm{W}$ [13], as well as for embrittled material [16]. A lay- 48 erwise chemical vapour (CVD) deposition process was used to 49 produce bulk samples [12]. Enhanced performance in compar- 50 ison to bulk W was shown for this CVD long fibre-reinforced 51 $\mathrm{W}$ composites $[12,16,17]$. In this contribution, we give a de- 52 tailed description of the evaluation of the fracture toughness of ${ }_{53}$ $\mathrm{W}_{\mathrm{f}} / \mathrm{W}$ with three-point-bending tests. Two different three point 54 bending test set-ups and an optical measurement system for real 55 time displacement evaluation and crack observation were used. 56 A first estimation of the toughness is given by utilising three- 57 point-bending tests according to ASTM E399 [2]. Similar to 58 studies on other $\mathrm{W}$ based materials [18] a provisional fracture toughness $\left(\mathrm{K}_{P}\right)$ was calculated. For a quantitative evaluation the J-Integral approach [19] typically used for tough materials according to ASTM E1820 [1] $\left(\mathrm{J}_{Q}\right)$ was applied on KLSTtype $\mathrm{W}_{\mathrm{f}} / \mathrm{W}$ samples [20]. Sequential loading and partial unloading allows the observation of the crack growth and the calculation of the J-Integral at various crack lengths [21]. This was supplemented by microstructural investigations of the fracture surfaces to obtain the active mechanisms. Finally, the microstructural findings, the results as well as the applicability of the ASTM E399 and ASTM E1820 for $\mathrm{W}_{\mathrm{f}} / \mathrm{W}$ are critically discussed.

\section{Material synthesis, sample preparation and experimen- tal procedure}

The bulk $\mathrm{W}_{\mathrm{f}} / \mathrm{W}$ investigated in this work was produced with a layerwise chemical vapor deposition process at approximately $650{ }^{\circ} \mathrm{C}$ described in [12]. Two types of unidirectional reinforced composite were produced. The first type had pure $\mathrm{W}$ fibres with a diameter of $150 \mu \mathrm{m}$ [22] which were coated with a $1 \mu \mathrm{m}$ erbia interlayer produced with magnetron sputtering according to [23]. This composite is called $\mathrm{W}_{\mathrm{f}} / \mathrm{W}_{\mathrm{Er}_{2} \mathrm{O}_{3}}$ in the following and had a fiber distance in every direction of around 120 $\mu \mathrm{m}$ with a fibre volume fraction between 21 and $22 \%$. The density was measured to be between 91.2 and $92.5 \%$ using a cross-section image. This method uses a processed microscopy image to distinguish between the pores (converted to black) and the dense material (converted to white) by calculating the black and white pixels within that image. The second composite 


\section{Nomenclature}

\begin{tabular}{|c|c|}
\hline \multicolumn{2}{|c|}{ Nomenclature } \\
\hline$\eta_{p l}$ & $\begin{array}{l}\text { function of the crack length in comparison to the } \\
\text { original specimen height }\end{array}$ \\
\hline$\gamma_{p l}$ & $\begin{array}{l}\text { function of the crack length in comparison to the } \\
\text { original specimen height }\end{array}$ \\
\hline$v$ & Poisson's ratio \\
\hline$a$ & crack length \\
\hline$a_{\text {initial }}$ & initial length of the crack \\
\hline$a_{\text {opening }}$ & $\begin{array}{l}\text { crack opening (measured for all } \mathrm{W}_{\mathrm{f}} / \mathrm{W}_{\mathrm{Y}_{2} \mathrm{O}_{3}} \text { speci- } \\
\text { mens) }\end{array}$ \\
\hline$a_{\text {surface }}$ & $\begin{array}{l}\text { the surface crack length at the front side of the } \mathrm{K}_{P} \\
\text { specimens }\end{array}$ \\
\hline$f(a / H)$ & dimensionless function defined in the standard \\
\hline$K_{Q J}$ & stress intensity factor \\
\hline $\mathrm{A}_{p l}$ & $\begin{array}{l}\text { area under the load-displacement curve without the } \\
\text { elastic part calculated from the slope of the curve }\end{array}$ \\
\hline $\mathrm{B}$ & specimen thickness \\
\hline CLSM & confocal laser scanning microscope \\
\hline CVD & chemical vapour deposition \\
\hline DBTT & ductile-to-brittle transition temperature \\
\hline $\mathrm{E}$ & Young's modulus \\
\hline EDM & electrical discharge machining \\
\hline $\mathrm{Er}_{2} \mathrm{O}_{3}$ & erbium oxide \\
\hline $\mathrm{H}$ & specimen height \\
\hline index i & cycle number \\
\hline $\mathrm{J}_{e l}$ & elastic part of the J-Integral \\
\hline $\mathrm{J}_{p l}$ & plastic part of the J-Integral \\
\hline $\mathrm{J}_{Q-i n i}$ & J-Integral value for crack initiation \\
\hline
\end{tabular}
$\eta_{p l} \quad$ function of the crack length in comparison to the original specimen heigh original specimen height
length of the crack
$\mathrm{Y}_{2} \mathrm{O}_{3}$ speci- the surface crack length at the front side of the $\mathrm{K}_{P}$ specimens
$K_{Q J} \quad$ stress intensity factor
$\mathrm{A}_{p l} \quad$ area under the load-displacement curve without the elastic part calculated from the slope of the curve
CLSM confocal laser scanning microscope
CVD chemical vapour deposition
DBTT ductile-to-brittle transition temperature
E Young's modulus
EDM electrical discharge machining
$\mathrm{Er}_{2} \mathrm{O}_{3}$ erbium oxide
specimen height

type was produced using $\mathrm{W}$ fabrics $[12,24]$ consisting of $\mathrm{K}$ doped W fibres with a diameter of $150 \mu \mathrm{m}[25,26]$ as warp
$\mathrm{J}_{Q-\max }$ maximum J-Integral value

$\mathrm{J}_{Q}$ or $\mathrm{J}_{i}$ provisional fracture toughness calculated according to ASTM E1820 [1]

$\mathrm{K}_{I C} \quad$ fracture toughness

$\mathrm{K}_{J-0.2}$ provisional fracture toughness calculated with the $\mathrm{J}_{Q}$ values at a crack length of $0.2 \mathrm{~mm}$

$\mathrm{K}_{J-1.5}$ provisional fracture toughness calculated with the $\mathrm{J}_{Q}$ values at a crack length of $1.5 \mathrm{~mm}$

$\mathrm{K}_{J-\max }$ provisional fracture toughness calculated with $\mathrm{J}_{Q-\max }$

$\mathrm{K}_{P_{\text {initial }}} \quad \mathrm{K}_{P}$ calculated with $a_{\text {initial }}$

$\mathrm{K}_{P_{\text {surface }}} \mathrm{K}_{P}$ calculated with $a_{\text {surface }}$

$\mathrm{K}_{P} \quad$ provisional fracture toughness calculated according to ASTM E399 [2]

$\mathrm{P} \quad$ load applied to the specimen $\left(\mathrm{K}_{P}\right.$ evaluation)

$\mathrm{P}_{\max } \quad$ maximum load during bending test $\left(\mathrm{K}_{\max }\right.$ evaluation $)$

$\mathrm{P}_{Q} \quad$ load values before the first significant load-drop $\left(\mathrm{K}_{P}\right.$ evaluation)

R-Curve resistance-curve

S span of three point bending test

$\mathrm{W}$ tungsten

$\mathrm{W}_{\mathrm{f}} / \mathrm{W}$ tungsten fibre-reinforced tungsten composite

$\mathrm{W}_{\mathrm{f}} / \mathrm{W}_{\mathrm{Er}_{2} \mathrm{O}_{3}} \quad \mathrm{~W}_{\mathrm{f}} / \mathrm{W}$ with erbia interlayer used for $\mathrm{K}_{P}$ evaluation in as-fabricated and annealed state

$\mathrm{W}_{\mathrm{f}} / \mathrm{W}_{\mathrm{Y}_{2} \mathrm{O}_{3}} \quad \mathrm{~W}_{\mathrm{f}} / \mathrm{W}$ with yttria interlayer used for $\mathrm{K}_{P}$ and $\mathrm{J}_{Q}$ evaluation in as-fabricated state and $\mathrm{K}_{P}$ evaluation in annealed state

$\mathrm{Y}_{2} \mathrm{O}_{3} \quad$ yttrium oxide

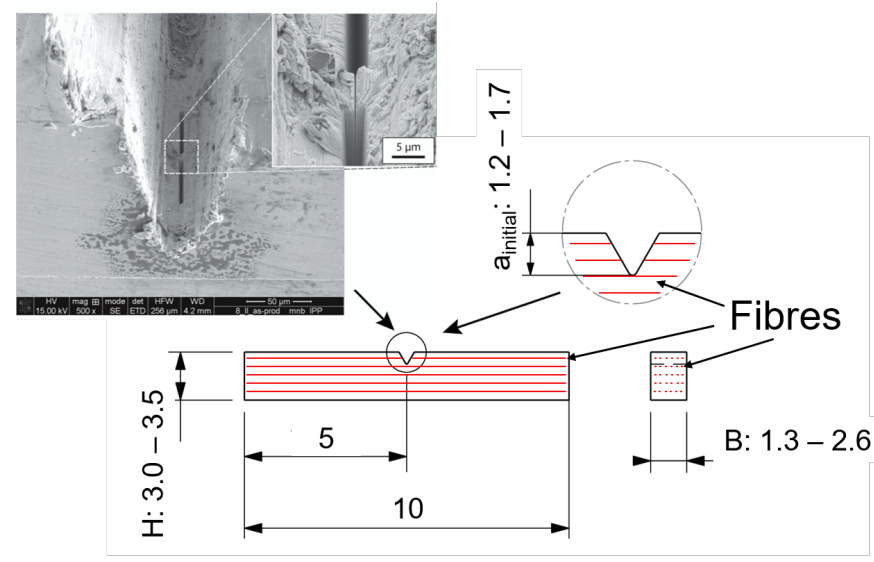

Figure 1: Bending specimen and artificial notch according to [18] for the samples tested according to ASTM E399. All dimensions are given in mm. 
75 Fig. 2).

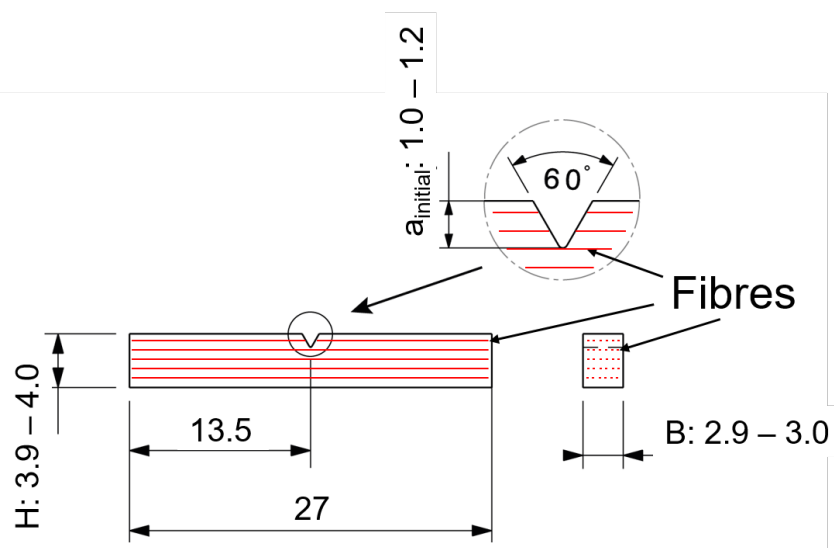

Figure 2: KLST - type geometry used for the Jo evaluation according to ASTM E1820. All dimensions are given in $\mathrm{mm}$. The $\mathrm{W}$ fibres are indicated in red.

An artificial sharp notch was used as pre-crack for all speci- ${ }^{122}$ mens, as fatigue pre-cracking was not possible due to the brit- ${ }^{123}$ tleness of the W-CVD matrix [18]. For all samples, at first, $a^{124}$ notch was cut with a diamond wire saw with a wire diameter of $0.3 \mathrm{~mm}$. For the $\mathrm{W}_{\mathrm{f}} / \mathrm{W}_{\mathrm{Er}_{2} \mathrm{O}_{3}}-\mathrm{K}_{P}$ specimens this was followed ${ }_{125}$ by a razor blade polishing and a final Focused Ion Beam (FIB) milling with a depth of 8.8 - $16.5 \mu \mathrm{m}$ similar as descried [18]. Such a notch is shown for in Fig. 1 . For the $\mathrm{W}_{\mathrm{f}} / \mathrm{W}_{\mathrm{Y}_{2} \mathrm{O}_{3}}-\mathrm{K}_{P}$ specimens and all KLST samples the diamond wire sawing was followed by wire sawing with a $0.03 \mathrm{~mm}$ thick W wire lubricated with a diamond particle oil suspension (average particle size $0.001 \mathrm{~mm}$ ). The $\mathrm{W}_{\mathrm{f}} / \mathrm{W}_{\mathrm{Y}_{2} \mathrm{O}_{3}}-\mathrm{K}_{P}$ samples were then FIB cut similar to the $\mathrm{W}_{\mathrm{f}} / \mathrm{W}_{\mathrm{Er}_{2} \mathrm{O}_{3}}-\mathrm{K}_{P}$ specimens. The KLST $-\mathrm{W}_{\mathrm{f}} / \mathrm{W}_{\mathrm{Y}_{2} \mathrm{O}_{3}-}-\mathrm{J}_{Q}$ specimens had a dual step wire sawing with a second wire di $^{-}{ }_{129}$ ameter of $0.03 \mathrm{~mm}$ with diamond oil suspension (average size ${ }_{130}$ of diamond-particles: $0.001 \mathrm{~mm}$ ). After the first tests it was $_{131}$ seen that the FIB milling was not necessary for the as-fabricated ${ }_{132}$ KLST samples as the crack growth always starts in the middle ${ }_{133}$ of the prepared notch. In addition, the notch refinement with the ${ }_{134}$ $0.03 \mathrm{~mm}$ wire saw had the same effect as the refinement with ${ }_{135}$ the razor blade and the change is caused by the lack of access ${ }_{136}$ to the razor blade notching machine. The overview of the notch ${ }_{137}$ preparation procedures is given in Tab. 1 .

\begin{tabular}{llll}
\multicolumn{4}{c}{ Table 1: Notch preparation procedures. } \\
Step & $\mathrm{W}_{\mathrm{f}} / \mathrm{W}_{\mathrm{Er}_{2} \mathrm{O}_{3}-\mathrm{K}_{P}}$ & $\mathrm{~W}_{\mathrm{f}} / \mathrm{W}_{\mathrm{Y}_{2} \mathrm{O}_{3}}-\mathrm{K}_{P}$ & $\mathrm{~W}_{\mathrm{f}} / \mathrm{W}_{\mathrm{Y}_{2} \mathrm{O}_{3}-\mathrm{J}_{Q}}$ \\
\hline 1 & $\mathrm{EDM}$ & $\mathrm{EDM}$ & EDM \\
2 & wire saw & wire saw & wire saw \\
& $(\varnothing 0.3 \mathrm{~mm})$ & $(\varnothing 0.3 \mathrm{~mm})$ & $(\varnothing 0.3 \mathrm{~mm})$ \\
3 & razor blade & wire saw & wire saw \\
& & $(\varnothing 0.03 \mathrm{~mm})$ & $(\varnothing 0.03 \mathrm{~mm})$ \\
4 & FIB-cut & FIB-cut & - \\
\hline
\end{tabular}

Both sample geometries $\left(\mathrm{K}_{P}\right.$ and $\left.\mathrm{J}_{Q}\right)$ were tested in as-149

\section{.}

envelopes to protect the $\mathrm{W}$ against carbonisation, as carbonisation leads to embrittlment and tungsten carbide formation as undesirable side effects [28]. The annealing led to an embrittlement of the fibres by massive grain growth $[5,18]$ and thus allowed the study of the effect of operational embrittlement. The different temperature treatments results from the use of pure [22] and K-doped W fibres [26] with different embrittlement temperatures. The $\mathrm{W}_{\mathrm{f}} / \mathrm{W}_{\mathrm{Er}_{2} \mathrm{O}_{3}}$ samples were heated to $1800{ }^{\circ} \mathrm{C}$ and $\mathrm{W}_{\mathrm{f}} / \mathrm{W}_{\mathrm{Y}_{2} \mathrm{O}_{3}}$ samples to $2200{ }^{\circ} \mathrm{C}$. Both annealing temperatures were held for $0.5 \mathrm{~h}$. The overview of the material types and usage is given in Tab. 2 .

The tests were performed with an universal testing device (TIRAtest 2820, No. R050/01, TIRA GmbH) at room temperature (RT). To determine displacement and crack growth on the surface, the load-displacement curves were correlated to an optical surface observation. For the optical surface observation an optical measurement system with a telecentric lens (OPTO ENGINEERING - TC4 M004-C) with a four times magnification was used in combination with a monochrome digital camera (Toshiba - Typ DU657M). For all $\mathrm{K}_{P}$ tests a $5 \mathrm{kN}$ load cell was used, while for the $\mathrm{J}_{Q}$ approach a $20 \mathrm{kN}$ load cell was used.

\subsection{Experiments according to ASTM E399 $\left(K_{P}\right)$}

The fracture toughness values were calculated by analysis of load-displacement curves, according to ASTM E399 with the following equation:

$$
K_{P}=\frac{P \cdot S}{B \cdot H^{3 / 2}} \cdot f(a / H)
$$

Where $\mathrm{K}_{P}$ is a provisional fracture toughness, $\mathrm{P}$ is the load applied to the specimen, $\mathrm{S}$ is the span $(8 \mathrm{~mm}), \mathrm{B}$ is the thickness, $\mathrm{H}$ is the height, $a$ is the crack length and $f(a / H)$ is a dimensionless function defined in the standard. $\mathrm{K}_{P}$ is for this specimen geometry defined as $\mathrm{K}_{I C}$ if two size criteria are fulfilled according to [2]. The first one defines the specimen height - crack length ratio $(0.45 \leq a / H \leq 0.55)$. The second size criterion defines the crack length $a$ and the specimen thickness B. Both have to be larger than $2.5 \cdot\left(\mathrm{K}_{P} / \sigma_{y}\right)^{2}$.

The determination of the crack length $/ a$ is complicated as the crack at the surface does not necessarily represent the real crack length in an inhomogeneous material like $\mathrm{W}_{\mathrm{f}} / \mathrm{W}$ [29]. Therefore, the initial length of the notch (artificial crack) $a_{\text {initial }}$ was used to calculate the provisional fracture toughness $\mathrm{K}_{P_{\text {initial }}}$ as a conservative estimation, because longer crack lengths necessarily lead to higher fracture toughness values. The surface crack length $a_{\text {surface }}$ of the front side was used to calculate the more realistic $\mathrm{K}_{P_{\text {surface }}}$. In addition, the crack opening $a_{\text {opening }}$ was measured for all $\mathrm{W}_{\mathrm{f}} / \mathrm{W}_{\mathrm{Y}_{2} \mathrm{O}_{3}}$ samples. In Fig. $3 a_{\text {initial }}, a_{\text {surface }}$ and $a_{\text {opening }}$ are indicated on a fractured sample.

The values of size, material combination, state, initial surface crack length and final surface crack length, for the specimens used for the $\mathrm{K}_{P}$ evaluation are summarized in Tab. 3 .

The tests were performed with a constant displacement rate of $0.5 \mu \mathrm{m} / \mathrm{s}$. 


\begin{tabular}{lllll} 
& \multicolumn{3}{c}{ Table 2: Material types and usage. } & \\
test method & material & W-fibre & material state & heat treatment \\
\hline $\mathrm{K}_{P}$ (ASTM E399) & $\mathrm{W}_{\mathrm{f}} / \mathrm{W}_{\mathrm{Er}_{2} \mathrm{O}_{3}}$ & pure & as-fabricated \& annealed & $1800{ }^{\circ} \mathrm{C}, 0.5 \mathrm{~h}$ \\
& $\mathrm{~W}_{\mathrm{f}} / \mathrm{W}_{\mathrm{Y}_{2} \mathrm{O}_{3}}$ & K-doped & as-fabricated \& annealed & $2200{ }^{\circ} \mathrm{C}, 0.5 \mathrm{~h}$ \\
$\mathrm{~J}_{Q}$ (ASTM E1820) & $\mathrm{W}_{\mathrm{f}} / \mathrm{W}_{\mathrm{Y}_{2} \mathrm{O}_{3}}$ & K-doped & as-fabricated & - \\
\hline
\end{tabular}

Table 3: Set of 3PB specimens for $\mathrm{K}_{P}$ estimation (ASTM E399) of two composites with and without heat treatment.

\begin{tabular}{|c|c|c|c|c|c|c|c|c|c|c|c|c|}
\hline No. & State & Interlayer & $\begin{array}{l}\mathrm{B} \\
{[\mathrm{mm}]}\end{array}$ & $\begin{array}{l}\mathrm{H} \\
{[\mathrm{mm}]}\end{array}$ & $\begin{array}{l}a_{\text {initial }} \\
{[\mathrm{mm}]}\end{array}$ & $a_{\text {ini. }} / \mathrm{H}$ & $\begin{array}{l}a_{\text {surface }} \\
{[\mathrm{mm}]}\end{array}$ & $a_{\text {sur. }} / \mathrm{H}$ & $\begin{array}{l}\mathrm{P}_{\max } \\
{[\mathrm{N}]}\end{array}$ & $\begin{array}{l}\mathrm{K}_{P_{\text {ini. }}} \\
{\left[\mathrm{MPa} \mathrm{m}^{1 / 2}\right]}\end{array}$ & $\begin{array}{l}\mathrm{K}_{\max } \\
{\left[\mathrm{MPa} \mathrm{m}^{1 / 2}\right]}\end{array}$ & 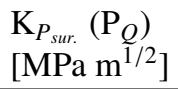 \\
\hline 1 & as-fab & $\mathrm{Er}_{2} \mathrm{O}_{3}$ & 2.3 & 3.4 & 1.7 & 0.5 & 2.8 & 0.8 & 883 & 39.6 & 190 & \\
\hline 2 & as-fab & $\mathrm{Er}_{2} \mathrm{O}_{3}$ & 2.3 & 3.5 & 1.7 & 0.4 & 2.9 & 0.8 & 585 & 25.5 & 130 & \\
\hline 4 & $\mathrm{emb}$ & $\mathrm{Er}_{2} \mathrm{O}_{3}$ & 2.2 & 3.4 & 1.3 & 0.4 & 2.0 & 0.6 & 294 & 10.2 & 18.3 & \\
\hline 5 & emb & $\mathrm{Er}_{2} \mathrm{O}_{3}$ & 2.2 & 3.0 & 1.2 & 0.4 & 1.9 & 0.6 & 198 & 9.1 & 20.5 & \\
\hline 6 & as-fab & $\mathrm{Y}_{2} \mathrm{O}_{3}$ & 2.0 & 3.4 & 1.3 & 0.4 & 2.9 & 0.9 & 603 & 23.0 & 215 & $144(452 \mathrm{~N})$ \\
\hline 8 & as-fab & $\mathrm{Y}_{2} \mathrm{O}_{3}$ & 2.0 & 3.4 & 1.2 & 0.4 & 2.9 & 0.9 & 611 & 22.3 & 241 & $167(516 \mathrm{~N})$ \\
\hline 9 & $\mathrm{emb}$ & $\mathrm{Y}_{2} \mathrm{O}_{3}$ & 1.6 & 3.4 & 1.4 & 0.4 & 2.1 & 0.6 & 154 & 7.6 & 14.8 & \\
\hline 10 & emb & $\mathrm{Y}_{2} \mathrm{O}_{3}$ & 2.0 & 3.4 & 1.7 & 0.5 & 2.2 & 0.7 & 155 & 8.0 & 15.0 & \\
\hline 11 & emb & $\mathrm{Y}_{2} \mathrm{O}_{3}$ & 1.3 & 3.4 & 1.7 & 0.5 & 2.6 & 0.7 & 89 & 7.1 & 13.6 & \\
\hline
\end{tabular}

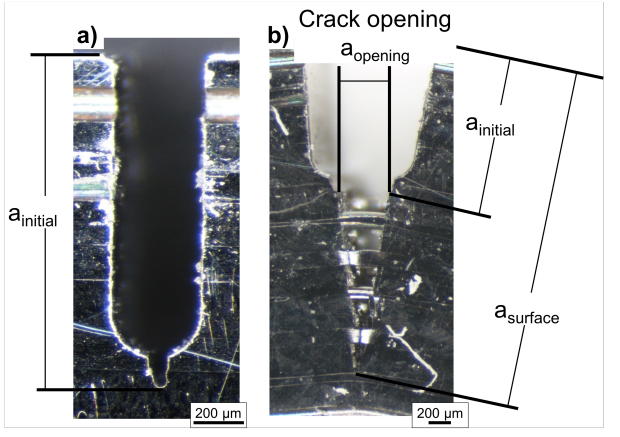

Figure 3: Initial, surface crack length and crack opening of typically $\mathrm{K}_{P}$ sample (specimen No.6).

\subsection{Experiments according to ASTM E1820 $\left(J_{Q}\right)$}

The J-Integral in the original sense is a path independent value of the stress concentration around, but excluding the crack ${ }^{179}$ tip [19]. The path independence only holds for straight cracks 180 in homogenous materials with unloaded crack surfaces [30]. By taking the whole amount of energy absorbed by the specimen into account, one can calculate a global J-Integral even for composites [31]. The loading of the crack surface has to be taken into account, too. This is due to the fact, that the energy absorbed within a composite material is not only in the crack tip but also behind the matrix crack tip, where delamination pullout, fibre-straining and fibre-fracture occurs.

The $\mathrm{J}_{Q}$ values, given in this paper, are evaluated based the 182 single-specimen method given in ASTM E1820. The speci-183 mens are cyclically loaded and unloaded, to calculate $\mathrm{J}_{Q}$ values 184 for different crack lengths precisely different crack resistances. 185 In this case the cyclic loading is displacement controlled. The ${ }_{186}$ loading with an average displacement of $8 \mu \mathrm{m}$ is higher than the ${ }_{187}$ unloading with an average of $3 \mu \mathrm{m}$ and therefore an increasing ${ }_{188}$

load is applied to the specimen. This unloading compliance method is a common single-specimen test technique to determine a J-R curve [21]. The test was performed with a constant displacement rate of $0.5 \mu \mathrm{m} / \mathrm{s}$.

The J-Integral is calculated as an elastic $\mathrm{J}_{e l}$ and a plastic $\mathrm{J}_{p l}$ part, as defined in ASTM E1820 as follows:

$$
\begin{gathered}
J_{(i)}=J_{e l(i)}+J_{p l(i)} \\
J_{e l(i)}=\frac{\left(K_{(i)}\right)^{2} \cdot\left(1-v^{2}\right)}{E}
\end{gathered}
$$

$$
\begin{aligned}
J_{p l(i)}= & {\left[J_{p l(i-1)}+\left(\frac{\eta_{p l(i-1)}}{b_{(i-1)}}\right)\left(\frac{A_{p l(i)}-A_{p l(i-1)}}{B}\right)\right] } \\
& \times\left[1-\gamma_{p l(i-1)}\left(\frac{a_{(i)}-a_{(i-1)}}{b_{(i-1)}}\right)\right]
\end{aligned}
$$

With the provisional $J_{(i)}$ which is called $J_{Q}$ in the following, a stress intensity factor $\mathrm{K}_{J}$ can be calculated as follows [1]:

$$
K_{J}=\sqrt{\frac{J_{Q} E}{\left(1-v^{2}\right)}}
$$

Whereby

$$
B>10 \frac{J_{Q}}{\sigma_{y}}
$$

is the size criterion for a valid test. $\mathrm{K}_{J}$ is the stress intensity factor calculated as described above with the span of $25 \mathrm{~mm}$. $\eta_{p l}$ and $\gamma_{p l}$ are functions of the crack length in comparison to the original specimen height, $\mathrm{A}_{p l}$ is the area under the loaddisplacement curve without the elastic part calculated from the slope of the curve, $\mathrm{E}$ is the Young's modulus and $v$ is the materials Poisson's ratio. The index $\mathrm{i}$ indicates the cycle number. The crack length for the calculation is idealized from $a_{\text {initial }}$ as 
zero crack propagation to the final crack length as it cannot ex-223 actly be determined in an inhomogeneous material as explained ${ }_{224}$ before. Heat tinting, known from steels and proposed in the 225 ASTM E1820, could not be applied as W shows strong oxida-226 tion with material losses. Instead, the final crack length was 227 marked trough thermoplastic infiltration. After the infiltration 228 of a thermoplastic the samples were cooled down with liquid ni-229 trogen and fully opened with an unilateral impact-stress (hammer).

The fracture surface was then investigated in an optical microscope and with a confocal laser scanning microscope (CLSM). The crack length formed during the test was measured on nine equally spaced positions for each sample. The nine white arrows in Fig. 4 b) indicate the final crack length for that sample after the test. The red line indicates the crack tip for this sample while in Fig. 4 a) and c) the back and front surface of the sample is shown.

As stable crack propagation was observed, equal steps between initial and final crack length were chosen to correlate crack propagation from the crack start and the end of the experiment. The initial crack length is the notch depth and the final crack length is the average crack length measured at nine positions as described before.

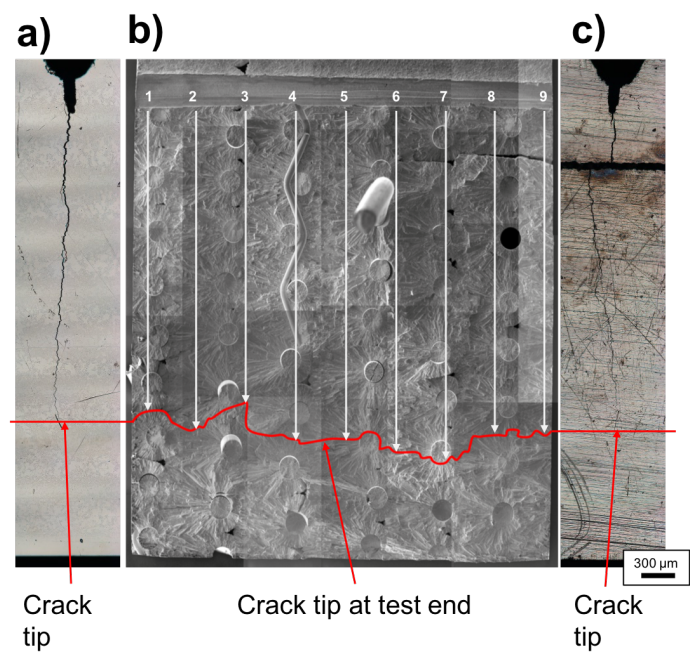

Figure 4: Crack length measurement of typically $\mathrm{J}_{Q}$ sample (specimen No. 13):235 Back side a), fracture surface b), front side c).

The specimen dimensions and the values for the initial and ${ }_{238}$ final crack lengths are given in Tab. 4. In addition, the $\operatorname{crack}_{239}$ opening $a_{\text {opening }}$ was measured at the end of experiment accord- ${ }_{240}$ ing to Fig. 3.

\section{Results}

\subsection{Fracture toughness according to ASTM E399 $\left(K_{P}\right)$}

Representative load-displacement diagrams, are shown for 246 an as-fabricated specimen (No. 6) in Fig. 5 and an embrit-247 tled specimen (No. 9) in Fig. 6. In both curves a non-linear 248 region is observed at the beginning caused by the setting of the 249 testing setup. The linear loading of the as-fabricated samples is 250

followed by a load drop (at $220 \mathrm{~N}$ ) (Fig. 5). The second larger load drop (at $454 \mathrm{~N}$ ) is followed by a non-linear increase in load and results in the maximum load $\left(\mathrm{P}_{\max }\right)$ of $603 \mathrm{~N}$. At that point a rapid expansion of $a_{\text {opening }}$ was visible at the specimen surface. With increased load a stable crack growth with crack deflection at the fibres is visible on the surface. The maximum load is followed by a stepwise failure.

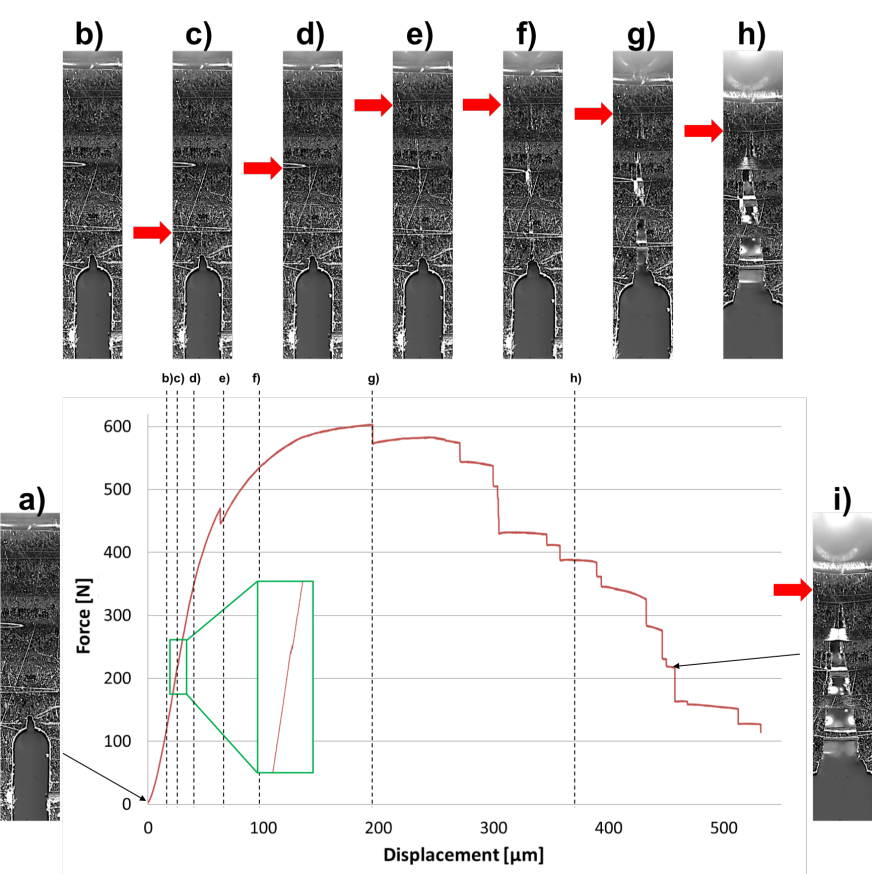

Figure 5: Load-displacement diagram for one as-fabricated specimen (No. 6). The rising load bearing capacity with surface crack growth and a large crack opening is visible. (a) $0 \mu \mathrm{m}$ displacment $/ 0 \mathrm{~N}$ load, b) $18 \mu \mathrm{m} / 139 \mathrm{~N}$, c) 26 $\mu \mathrm{m} / 220 \mathrm{~N}$, d) $39 \mu \mathrm{m} / 346 \mathrm{~N}$, e) $63 \mu \mathrm{m} / 448 \mathrm{~N}$, f) $99 \mu \mathrm{m} / 540 \mathrm{~N}, \mathrm{~g}) 195 \mu \mathrm{m} / 603$ $\mathrm{N}$, h) $369 \mu \mathrm{m} / 388 \mathrm{~N}$ und i) $457 \mu \mathrm{m} / 217 \mathrm{~N}$ ). The red arrows mark the crack tip in each picture.

During the loading of the embrittled sample a load drop at $146 \mathrm{~N}$ is observed (Fig. 6). This is followed by the maximum load $\mathrm{P}_{\max }(154 \mathrm{~N})$ and a large load drop. The crack growth during loading up to the maximum load could not be observed by the optical monitoring because, the surface roughness of the embrittled samples was to high: the samples were only polished before the heat treatment as it was done with all specimens. The composite was still able to bear some load after $\mathrm{P}_{\max }$.

After crack initiation the composite was, in both cases, still able to bear an increasing load. Therefore, the visible crack length was added to the initial crack length $\left(a_{\text {initial }}\right)$, resulting in the surface crack length $a_{\text {surface }}$ (see Fig. 3 for clarification). Fig. 7 exemplifies the selection of the loads used for the fracture toughness evaluation. For $a_{\text {surface }}$ the maximum load was used as $\mathrm{P}\left(\mathrm{P}_{\max }\right)$ to calculate $\mathrm{K}_{\max }$. For the as-fabricated $\mathrm{W}_{\mathrm{f}} / \mathrm{W}_{\mathrm{Y}_{2} \mathrm{O}_{3}}$ specimens the values before the first significant load-drop was used for further evaluations and is called $\mathrm{P}_{Q}$. For the embrittled samples the maximum load and correlating $a_{\text {surface }}$ was used. The results for the fracture toughness evaluation are summarized in Tab. 3.

The mean $\mathrm{K}_{\max }$ fracture toughness value for the as-fabricated 


\begin{tabular}{|c|c|c|c|c|c|c|c|c|}
\hline No. & $\begin{array}{l}\mathrm{B} \\
{[\mathrm{mm}]}\end{array}$ & $\begin{array}{l}\mathrm{H} \\
{[\mathrm{mm}]}\end{array}$ & $\begin{array}{l}a_{\text {initial }} \\
{[\mathrm{mm}]}\end{array}$ & $\begin{array}{l}a_{\text {final }} \\
{[\mathrm{mm}]}\end{array}$ & $\begin{array}{l}\mathrm{i}_{\text {crackstart }} \\
{[-]}\end{array}$ & $\begin{array}{l}\mathrm{J}_{Q-\text { initial }} \\
{\left[\mathrm{kJ} / \mathrm{m}^{2}\right]}\end{array}$ & $\begin{array}{l}\mathrm{J}_{Q-\max } \\
{\left[\mathrm{kJ} / \mathrm{m}^{2}\right]}\end{array}$ & $\begin{array}{l}\mathrm{K}_{J-\max } \\
{\left[\mathrm{MPa} \mathrm{m}^{1 / 2}\right]}\end{array}$ \\
\hline 12 & 3.0 & 4.0 & 1.2 & 3.3 & 3 & 0.04 & 5.8 & 51.1 \\
\hline 13 & 3.0 & 4.0 & 1.0 & 3.20 & 2 & 0.04 & 7.5 & 57.6 \\
\hline 14 & 3.0 & 3.9 & 1.0 & 3.1 & 4 & 0.07 & 6.4 & 47.7 \\
\hline 15 & 3.0 & 4.0 & 1.2 & 3.1 & 3 & 0.03 & 5.2 & 51.1 \\
\hline 16 & 2.9 & 4.0 & 1.1 & 3.5 & 1 & 0.03 & 6.6 & 53.8 \\
\hline
\end{tabular}

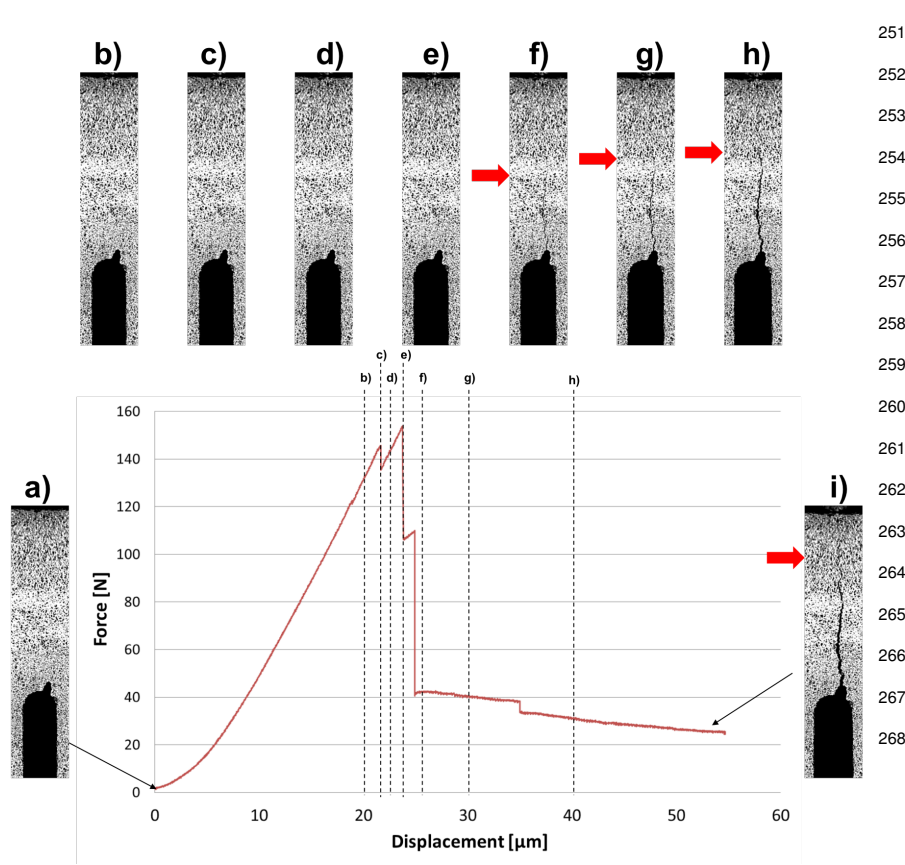

Figure 6: Load-displacement diagram for one embrittled specimens (No. 9). A rising load bearing after crack initiation is to be observed. The crack growth on the surface is observable after the maximum load. (a) $0 \mu \mathrm{m}$ displacement $/ 0$ $\mathrm{N}$ load, b) $20 \mu \mathrm{m} / 133 \mathrm{~N}$, c) $21,6 \mu \mathrm{m} / 146 \mathrm{~N}$, d) $22 \mu \mathrm{m} / 139 \mathrm{~N}$, e) $23,8 \mu \mathrm{m} / 107$ $\mathrm{N}$, f) $25 \mu \mathrm{m} / 41 \mathrm{~N}$, g) $30 \mu \mathrm{m} / 40 \mathrm{~N}, \mathrm{~h}) 40 \mu \mathrm{m} / 31 \mathrm{~N}$ und i) $54 \mu \mathrm{m} / 26 \mathrm{~N}$ ). The red arrows mark the crack tip in each picture.

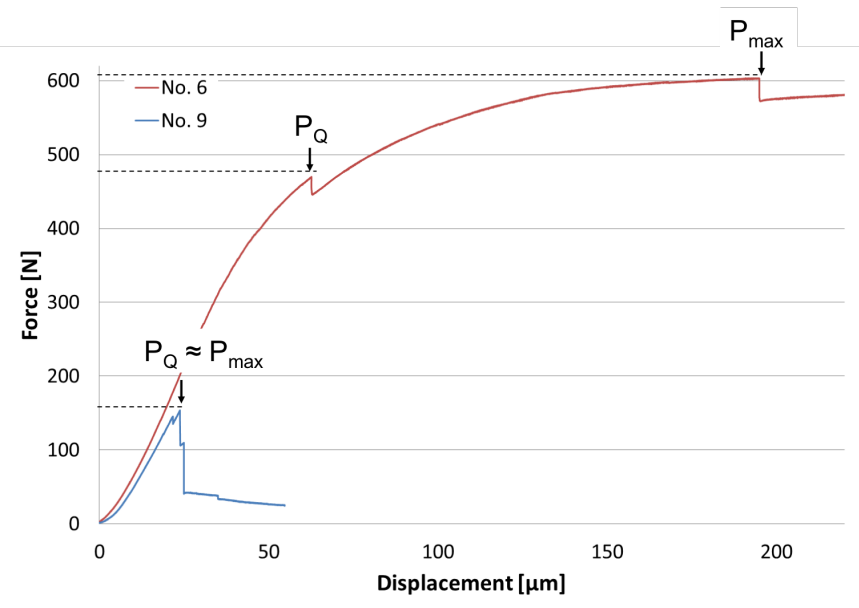

Figure 7: Load-displacement diagrams for one as-fabricated (No. 6: red) and one embrittled specimens (No. 9: blue). The loads $\mathrm{P}_{Q}$ and $\mathrm{P}_{\max }$ which were taken for the $\mathrm{K}_{P}$ and $\mathrm{K}_{\text {max }}$ evaluation are shown.
${ }_{251} \mathrm{~W}_{\mathrm{f}} / \mathrm{W}_{\mathrm{Er}_{2} \mathrm{O}_{3}}$ is $161 \pm 30 \mathrm{MPa} \mathrm{m}^{1 / 2}$, for the $\mathrm{W}_{\mathrm{f}} / \mathrm{W}_{\mathrm{Y}_{2} \mathrm{O}_{3}}$ it is $206 \pm 29$ $252 \mathrm{MPa} \mathrm{m}^{1 / 2}$. This is by one order of magnitude higher then the 253 mean values of $15 \pm 5 \mathrm{MPa} \mathrm{m}{ }^{1 / 2}$ for $\mathrm{W}_{\mathrm{f}} / \mathrm{W}_{\mathrm{Er}_{2} \mathrm{O}_{3}}$ and $14 \pm 1 \mathrm{MPa}$ 54 5 $\mathrm{m}^{1 / 2}$ for $\mathrm{W}_{\mathrm{f}} / \mathrm{W}_{\mathrm{Y}_{2} \mathrm{O}_{3}}$ in the embrittled case. No influence of the different heat treatments, interlayer material and fiber volume fractions was observed during the tests and evaluation.

The surface observation of the crack growth allowed to visualise the rising resistance against crack growth in a so called resistance-curve (R-Curve). The high quality optical measurement system was only available for the $\mathrm{W}_{\mathrm{f}} / \mathrm{W}_{\mathrm{Y}_{2} \mathrm{O}_{3}}$ samples and no crack growth during loading up to the maximum load could be observed for the embrittled samples. Therefore, only the RCurves for the $\mathrm{W}_{\mathrm{f}} / \mathrm{W}_{\mathrm{Y}_{2} \mathrm{O}_{3}}$ samples were calculated. The values for the R-Curve were calculated by defining specific points on the load-displacement curves. At that points, the crack length was measured on the sample surface and the $\mathrm{K}$ values were calculated with the associated load. The calculated R-Curves for three specimens are shown in Fig. 8.

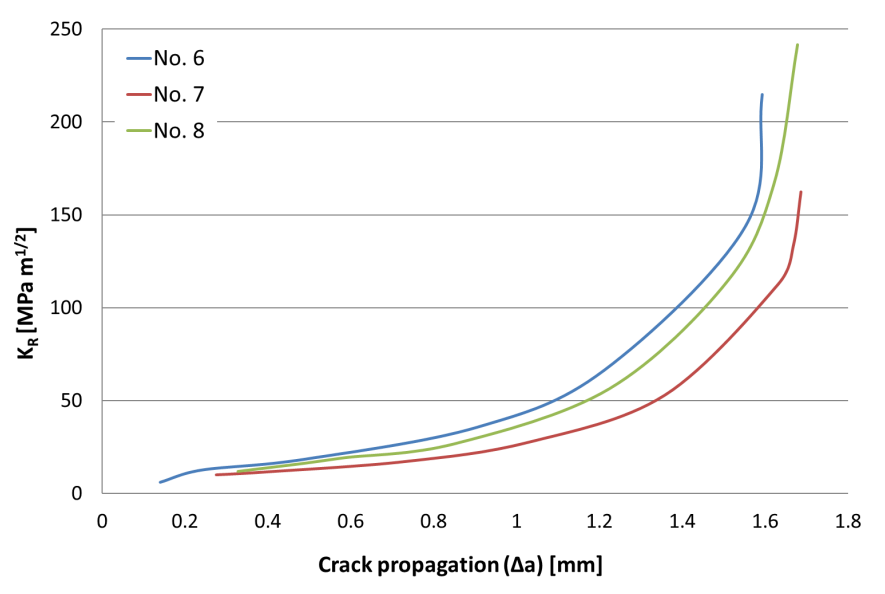

Figure 8: R-curve for $\mathrm{W}_{\mathrm{f}} / \mathrm{W}_{\mathrm{Y}_{2} \mathrm{O}_{3}}$, tested according to ASTM399 in the asfabricated state.

A typical fracture surface of the as-fabricated sample No. 6 with $\mathrm{Y}_{2} \mathrm{O}_{3}$ interlayer is shown in Fig. 9. This specimen shows only plastically deformed $\mathrm{W}$ fibres with the typically knife edge fracture (Fig. 9 c)) [32]. The W matrix in Fig. 9 a) is nearly fully dense $(99.3 \%)$ and the typical corona shape of the CVDW $[33,34,35]$ can be seen. Near the fibres, the matrix shows mainly intergranular fractureed small grains (Fig. 9 d), e)). Nearly all bigger $\mathrm{W}$ grains show transgranular fracture (Fig. $9 \mathrm{~b}$ )). The interlayer (in this case $\mathrm{Y}_{2} \mathrm{O}_{3}$ ) does not show any damage and sticks to the matrix (Fig. 9 b)-e)). Hence, the fibre 

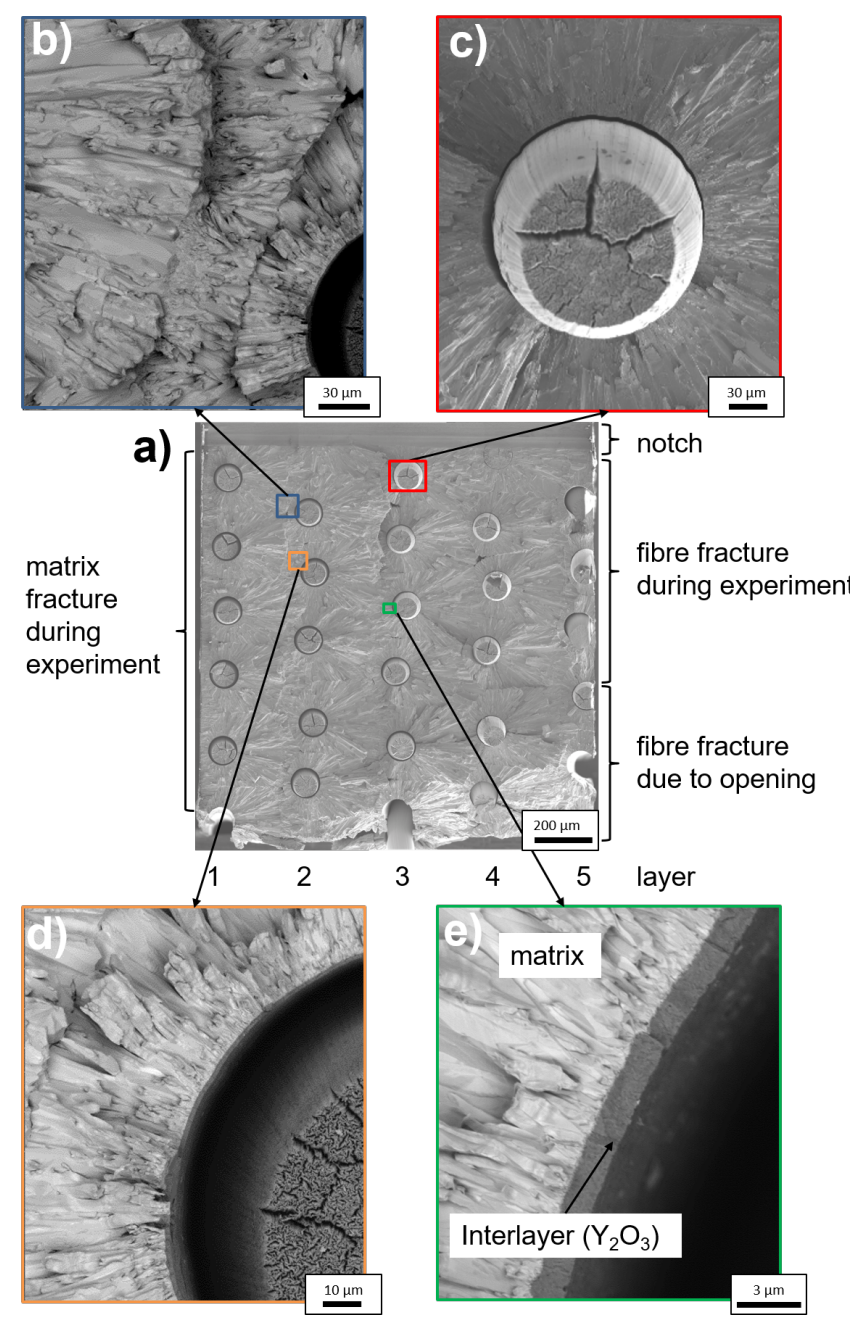

Figure 9: Typical fracture surface of specimen No. 6 with detailed views of the fractured matrix (b)), fractured fibre (c)) and the $\mathrm{Y}_{2} \mathrm{O}_{3}$ interlayer region (d), e)).
A typical fracture surface of an embrittled samples is shown in Fig. 10 (sample No. 9, $\mathrm{Y}_{2} \mathrm{O}_{3}$ interlayer). In that case all fibres in all specimens fractured brittle and showed mainly cleavage with scattered spots of intergranular fracture (Fig. $10 \mathrm{~d}$ )). In the matrix visible in Fig. $10 \mathrm{c}$ ), d), pores or bubbles at the fractured grain bounderies are visible. One possible explanation for the pores is the deposition of the fluorine of the precursor gas during the CVD process which leads to a pore formation during the heat treatment [36]. At these locations, the matrix fractured intergranular. The heated/embrittled $\mathrm{W}$ matrix showed more transgranular fracture as the $\mathrm{W}$ grains are bigger than in the asfabricated state (Fig. $10 \mathrm{c}$ )). The thickness of the $\mathrm{Y}_{2} \mathrm{O}_{3}$ interlayer is strongly reduced and on some spots grain growth from the matrix to the fibre was observed (Fig. $10 \mathrm{e}$ )). This was not observed for $\mathrm{Er}_{2} \mathrm{O}_{3}$. Both interlayers $\left(\mathrm{Er}_{2} \mathrm{O}_{3}\right.$ and $\left.\mathrm{Y}_{2} \mathrm{O}_{3}\right)$ were fractured and stick to the matrix as well as to the fibres (Fig. 10 d), e)).

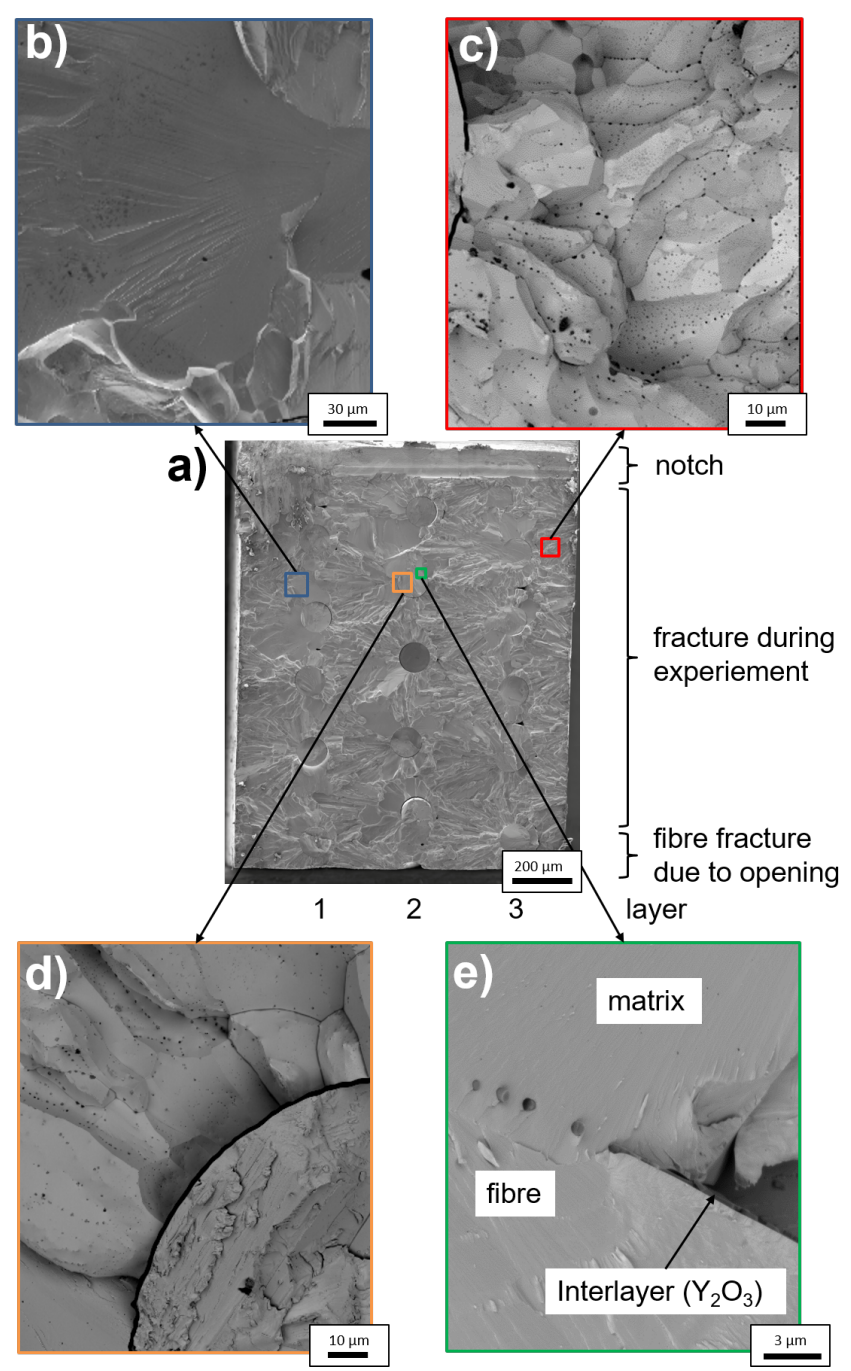

Figure 10: Typical fracture Surface of Specimen No. 9 with detailed views of the fractured matrix (b)), fractured matrix (c)) and the $\mathrm{Y}_{2} \mathrm{O}_{3}$ interlayer region (d), e)). 


\subsection{Results according to ASTM E1820 ( $\left.J_{Q}\right)$}

Fig. 11 shows the load-displacement diagram of the repre- ${ }^{317}$ sentative specimen No. 16.

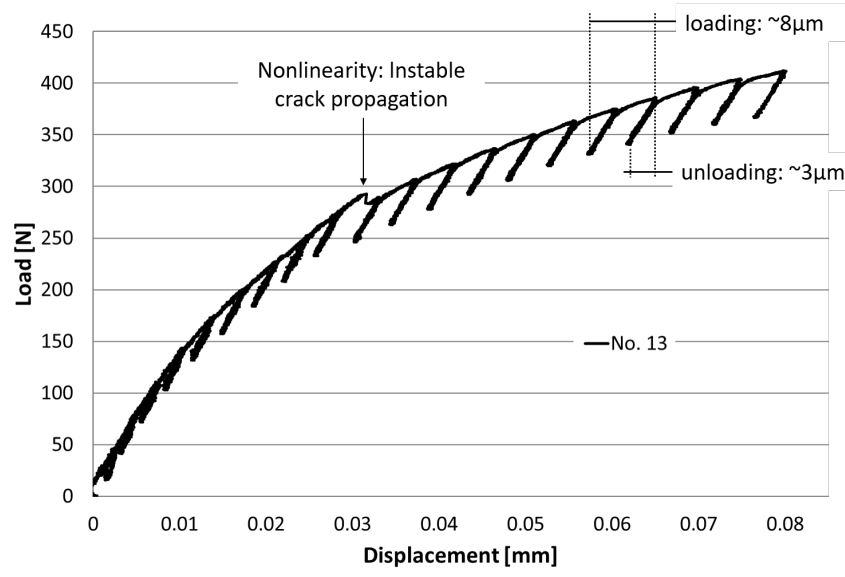

Figure 11: Typical load-displacement diagram of the $\mathrm{J}_{Q}$ test of Specimen No. 13. All specimens were cyclically loaded with a displacement of $8 \mu \mathrm{m}$ followed by an unloading of $3 \mu \mathrm{m}$.

The only macroscopic drop visible in the curve appears due to an instable crack propagation. The $\mathrm{J}$-values for crack initia- ${ }^{32}$ tion are measured to be $\mathrm{J}_{Q \text {-initial }}=0.04 \pm 0.02 \mathrm{~kJ} / \mathrm{m}^{2}$. The $\max { }^{-}{ }^{322}$ imum $\mathrm{J}$-values are $\mathrm{J}_{Q-\max }=6.3 \pm 0.9 \mathrm{~kJ} / \mathrm{m}^{2}$. The $\mathrm{J}$-R-curves ${ }^{323}$ are similar for all specimens (Fig. 12). Only specimen No. $16^{324}$ shows a slightly flatter J-R-curve. The crack growth on the sur- ${ }^{325}$ face is comparable with the $\mathrm{W}_{\mathrm{f}} / \mathrm{W}_{\mathrm{Y}_{2} \mathrm{O}_{3}}-\mathrm{K}_{P}$ samples were with ${ }^{32}$ increased load a stable crack growth is visible on the surface. The provisional fracture toughness $\mathrm{K}_{J-\max }$ was calculated for the maximum $\mathbf{J}_{Q}$ value $\mathrm{J}_{Q-\max }$. Tab. 4 summarises all the results for the $\mathrm{J}_{Q}$ evaluation.

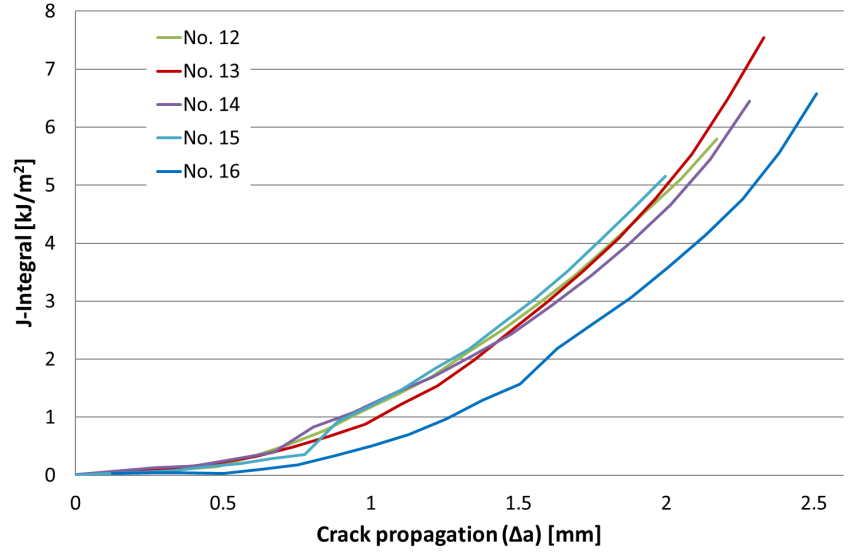

Figure 12: J-R-curves for the J-Integral test. The resistances against crack $^{334}$ growth is growing with rising crack propagation.

Fig. 13 a) shows the fracture surfaces of the specimens No. 337 13 which had an optical density of almost $100 \%$. The fracture 338 surface of specimen No. 16 with an optical density of $94 \%$ is shown in Fig. 13 b). The red line marks the final crack tip. The 340 fracture surfaces of all specimens show the typical corona shape 341

Figure 13: Fracture surface of specimen No. 13 (a)) and No. 16 (b)). The red line marks the crack front which was formed within the experiment. The cavities in the fracture surface of No. 16 (b) are unfilled pores which results in the high porosity.

The calculated fracture toughness values $\mathrm{K}_{J}$ corresponding different $\mathrm{J}$-values at different crack length are shown in Tab. 5. This points were chosen as comparison to other materials $[20,21,1]$. The $\mathrm{K}_{J-0.2}$ were calculated with the loads at a crack length of $0.2 \mathrm{~mm}$ and the $\mathrm{K}_{J-1.5}$ corresponds to the loads at a crack length of $1.5 \mathrm{~mm}$.

Table 5: $\mathrm{K}_{J}$ calculation from different $\mathrm{J}$ values $\mathrm{W}_{\mathrm{f}} / \mathrm{W}$.

\begin{tabular}{lllll} 
No. & $\mathrm{J}_{0.2}$ & $\mathrm{~K}_{J-0.2}$ & $\mathrm{~J}_{1.5}$ & $\mathrm{~K}_{J-1.5}$ \\
& {$\left[\mathrm{~kJ} / \mathrm{m}^{2}\right]$} & {$\left[\mathrm{MPa} \mathrm{m}^{1 / 2}\right]$} & {$\left[\mathrm{kJ} / \mathrm{m}^{2}\right]$} & {$\left[\mathrm{MPa} \mathrm{m}^{1 / 2}\right]$} \\
\hline 12 & 0.06 & 5.2 & 2.5 & 33.2 \\
13 & 0.08 & 5.8 & 2.5 & 33.0 \\
14 & 0.05 & 4.6 & 3.0 & 36.5 \\
15 & 0.10 & 6.7 & 2.4 & 32.8 \\
16 & 0.04 & 4.4 & 1.6 & 26.3 \\
\hline
\end{tabular}

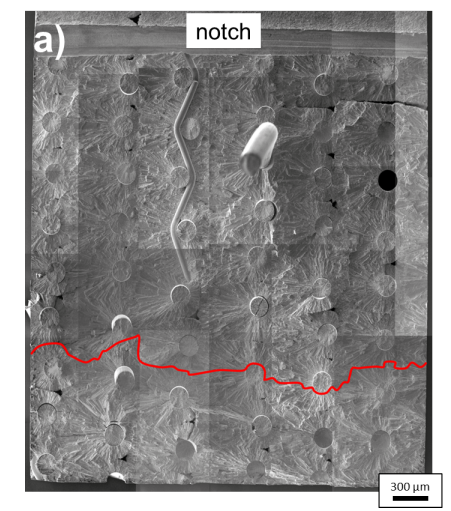

of the CVD-W $[33,34]$. In all cases more than $90 \%$ transgranular fracture of the CVD-matrix can be observed. Only the small near the fibres show intergranular fracture. As $\mathrm{a}_{\text {opening }}$ at the tests was below $30 \mu \mathrm{m}$ (W fibre elongation at fracture: 51 $\mu \mathrm{m}[25])$ no fibre was fractured during the test.

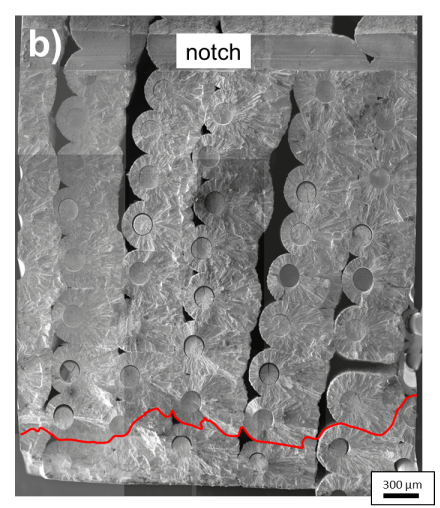

\section{Discussion}

\subsection{Discussion of $K_{P}$ results}

\section{As-fabricated samples}

The representative curve of the as-fabricated sample (Fig. 5) showed a first load drop after elastic loading followed by a deviation from the elastic slope. This is followed by a further load drop before the curve begins to flatten and the maximum load is reached. More load drops can be seen after having reached maximum load until the composites breaks. In the present study, the microstructural investigation showed that the debonding for both interlayer materials $\left(\mathrm{Er}_{2} \mathrm{O}_{3}\right.$ and $\left.\mathrm{Y}_{2} \mathrm{O}_{3}\right)$ is observed between fibre and interlayer and all fibres failed ductile with the typical necking and knife-edge fracture surface as described before [32]. Fibre pull out could not be observed caused as in a three point bending test the stress peak is in the centre of the 
specimen.

This behaviour is typical for tough composites reinforced with ductile fibres as shown for other composite materials in [37, 38, 39]. In such and in our materials, the first load drop corresponds to crack initiation in the matrix, the flattening of the curve is caused by the ductile deformation of the fibres, the ultimate load is determined by the strength of the fibres and the load drops are caused by multiple fibre fracture. These effects are all caused by extrinsic toughening mechanisms and the load transfer from the matrix to the fibres is governed by the interaction with the interlayer.

The extrinsic toughening mechanisms which are typically active in $\mathrm{W}_{\mathrm{f}} / \mathrm{W}$ were already found to be energy dissipation by fibre-matrix interface debonding and crack deflection, crack bridging by intact fibres, ductile deformation of fibres and pull out of fractured fibres from the matrix $[13,26,40]$. The 399 first mechanisms which become active after crack initiation are ${ }_{400}$ debonding, crack deflection. Crack meandering has a only a $\mathrm{a}_{401}$ low contribution to the load bearing capacity as load transfer ${ }_{402}$ is directly accomplished by the crack bridging of the intact fi-403 bres. The crack bridging is the main mechanism as long as the ${ }_{404}$ fibres are able to bear the rising load. Once the load exceeds 405 the yield stress of the fibres ductile deformation takes place and ${ }_{406}$ the ductile deformation is assumed to be the dominant and most ${ }_{407}$ effective mechanism [13]. The fibres enable a large scale crack ${ }_{408}$ bridging due to their large fracture strain (compared to the ma-409 trix) as known from other composites [41, 42]. With increasing ${ }_{410}$ load and displacement the crack opening of the specimen is in-411 creasing.

As the mechanisms act behind the crack tip there is a large $e_{413}$ zone which can be seen as plastic zone behind the crack tip. ${ }_{414}$ In addition, the plane strain condition is not predominate in the ${ }_{415}$ crack tip from a certain crack opening on as the loading condi- ${ }_{416}$ tions changes. Therefore a valid plane strain fracture toughnesS 417 cannot be calculated using the ASTM E399 at which this is a $a_{418}$ main requirement. To ensure that the plastic zone is small com- ${ }^{4} 19$ pared to the specimen cross section and therefore the specimen ${ }_{420}$ fracture under nominally linear elastic conditions [21], two size 421 criteria from the ASTM E399 needs to be fulfilled to calcu-422 late the fracture toughness $\mathrm{K}_{I C}$. The first criteria which defines ${ }_{423}$ the specimen height - crack length ratio is only be fulfilled if ${ }_{424}$ the $\mathrm{K}_{I C}$ is calculated with $a_{\text {initial }}$ (see Tab. 3). However, $a_{\text {initial } 425}$ is only the starting crack length and with increasing load, the ${ }_{426}$ crack is growing. The second size criterion ( $a$ and $\mathrm{B} \geq 2.5_{427}$ - $\left.\left(\mathrm{K}_{P} / \sigma_{y}\right)^{2}\right)$ can be calculated with the tensile strength of $480_{428}$ $\mathrm{MPa}$ for $\mathrm{W}_{\mathrm{f}} / \mathrm{W}_{\mathrm{Er}_{2} \mathrm{O}_{3}}$ [17] and $231 \mathrm{MPa}$ for $\mathrm{W}_{\mathrm{f}} / \mathrm{W}_{\mathrm{Y}_{2} \mathrm{O}_{3}}$ [43]. Both ${ }_{429}$ size criteria given in the ASTM E399 cannot be considered as 430 fulfilled for the as-fabricated case as the samples are too small. 431 If we look at small crack opening where bending in the spec-432 imen is small the plane stress state is still valid and the calcu-433 lation of $\mathrm{K}_{P}$ values might be possible. To ensure small crack ${ }_{434}$ openings, the load $\mathrm{P}_{Q}$ (Fig. 7) was chosen to calculate $\mathrm{K}_{P}$. The ${ }_{435}$ crack openings, the corresponding force values and the values 436 of this calculations are shown Tab. 6 .

\section{Embrittled samples} linear loading and after a first load drop no deviation of the ${ }_{440}$

Table 6: Crack opening and resulting $\mathrm{K}_{P_{\text {surface }} \text { values for } \mathrm{W}_{\mathrm{f}} / \mathrm{W}_{\mathrm{Y}_{2} \mathrm{O}_{3}} \text { specimens. }}$
\begin{tabular}{lllll}
\hline No. & $a_{\text {surface }}$ & $a_{\text {opening }}$ & $\mathrm{P}$ & $\mathrm{K}_{P}$ \\
& {$[\mu \mathrm{m}]$} & {$[\mu \mathrm{m}]$} & {$[\mathrm{N}]$} & {$\left[\mathrm{MPa} \mathrm{m}^{1 / 2}\right]$} \\
\hline $6-\mathrm{P}_{Q}$ & 2870 & 19 & 452 & 143 \\
$6-\mathrm{P}_{\max }$ & 2905 & 128 & 603 & 214 \\
\hline $7-\mathrm{P}_{Q}$ & 2900 & 27 & 460 & 133 \\
$7-\mathrm{P}_{\max }$ & 2920 & 128 & 538 & 162 \\
\hline $8-\mathrm{P}_{Q}$ & 2860 & 20 & 516 & 167 \\
$8-\mathrm{P}_{\max }$ & 2940 & 103 & 611 & 241
\end{tabular}

linear slope. This is followed by a linear rising of the load. After reaching the maximum a sharp drop in the load occurred. This is followed by further load drops before the material fails completely. The microstructural investigation of the tested sample shows interlayer debonding and that all fibres fractured brittle.

The mechanisms which are typically active in a embrittled $\mathrm{W}_{\mathrm{f}} / \mathrm{W}$ sample are fibre-matrix interface debonding and crack deflection, crack bridging by intact fibres and pull out of fractured fibres from the matrix [40]. Pull out is not active in a three point bending test as the stress peak is in the centre of the specimen and thus all fibres fail in the centre. In addition, the brittle fibres have a low fracture strain $(\sim 0.1 \%)$ and low tensile strength (896 MPa)[22] which is comparable with the tungsten matrix [33]. As in the as-fabricated samples, the first mechanisms which become active after crack initiation are debonding, crack deflection and crack meandering. This is followed by crack bridging of intact fibres, this is the main mechanism in the embrittled state. Once the load exceeds the fracture stress of the fibres they are failing brittle.

After the first load drop the load transfer from the matrix to fibre is accomplished by the debonding and frictional interaction of the fibres with the interlayer material and the fibres which are bridging the crack by elastic deformation. As the fracture strain of the fibres is relatively low, the specimen crack opening (crack bridging of the fibres) and thus bending before fracture is relatively small. Hence, the plane strain condition is predominate in the crack tip and the derived fracture toughness can be considered as valid within standard ASTM E399.

Only for sample No. 5 the first size criteria can be achieved. As no data exists about the ultimate tensile strength of embrittled $\mathrm{W}_{\mathrm{f}} / \mathrm{W}$ the second size criteria is estimated using the tensile strength of the embrittled W-fibres [22] with the corresponding fibre fraction and the tensile strength of the matrix materials [44] . This results in the tensile strength of $253-448 \mathrm{MPa}$ for $\mathrm{W}_{\mathrm{f}} / \mathrm{W}_{\mathrm{Er}_{2} \mathrm{O}_{3}}$ and $306-404 \mathrm{MPa}$ for $\mathrm{W}_{\mathrm{f}} / \mathrm{W}_{\mathrm{Y}_{2} \mathrm{O}_{3}}$. The second size criteria can can be achieved for specimen No. 3 if calculated with $448 \mathrm{MPa}$. So, the plane strain condition, the first size criteria (for one specimen) and the second (for one specimen), are fulfilled and therefore the values for the embrittled case seems to be reliable. 


\subsection{Discussion of J-Integral testing and $J_{Q}$ results}

The J-Integral testing with the cyclic loading and unloading ${ }^{49}$ (Fig. 11) of the samples lead to a stable crack growth visible ${ }^{498}$ on the surface of the specimen. The loading of the specimen ${ }^{499}$ was stopped at crack openings between a minimum of $21 \mu \mathrm{m}^{500}$ (No. 15) to a maximum of $29 \mu \mathrm{m}$ (No. 13) to minimize bend- ${ }^{501}$ ing at the crack tip and therefore achieve plane strain conditions ${ }^{502}$ at the crack tip. With these small openings the $\mathrm{W}$ fibres were ${ }^{503}$ only elastically loaded as the used W fibres $(\varnothing 150 \mu \mathrm{m})$ have $\mathrm{a}^{504}$ lower yield elongation [25, 22]. As the elongation for failure is ${ }^{505}$ $57 \mu \mathrm{m}$ [25], no fibre was fractured during the tests. This means ${ }^{506}$ that after the matrix fractured during the test, the crack was ${ }^{507}$ bridged by the elastically loaded fibres. In absence of ductile ${ }^{508}$ fibre deformation, the mechanisms active are energy dissipa ${ }^{509}$ tion by fibre-matrix interface debonding and crack deflection ${ }^{510}$ and the crack bridging by intact fibres. The main mechanism ${ }^{511}$ which contributes to the fracture toughness is the large scale ${ }^{512}$ crack bridging as know from other composites [41, 42]. $\operatorname{In}^{513}$ the as-fabricated case the contribution of the fibres is increas ${ }^{514}$ ing with larger crack opening and thus the fracture toughness ${ }^{515}$ is also increasing. Larger crack openings needs to be seen in combination with the need of ensuring plane strain conditions ${ }^{516}$ at the crack tip. For that reason larger crack openings with plane ${ }^{517}$ strain conditions at the crack tip can only be achieved if the $\mathrm{e}^{518}$ specimen size will be increased and thus bending in the $\mathrm{crack}^{519}$ tip will be minimized. In a next step larger specimens should be ${ }^{520}$ tested which will allow to load the fibres till failure and as the ${ }^{521}$ ductile fibre deformation is assumed to be the dominant mech ${ }^{522}$ anism [13] to calculate the maximum $\mathrm{J}_{Q}$.

\subsection{Fracture behaviour and consequences for $W_{f} / W$}

The evaluated R-Curves (Fig. 8) and the J-R-curves (Fig.527 12) have a concave shape without any plateaus. This is in con-528 trast to the R-Curves for homogeneous ductile materials which 529 show a convex shape with a plateau at larger crack lengths [21].530 That means, that the resistance against crack growth in homoge-531 neous ductile materials reaches a maximum value for a defined 532 crack length. This is not the case for fibre reinforced composite 533 and thus for $\mathrm{W}_{\mathrm{f}} / \mathrm{W}$ as the extrinsic toughening mechanism [26] $]_{53}$ become more and more active behind the crack tip and there-535 fore the resistance against crack growth is rising as the crack is 536 growing. This behaviour is caused by the large scale bridging ${ }_{537}$ conditions and known from other fibre reinforced composites538 [42]. Especially the crack bridging and ductile deformation of 539 the fibres which become active at large crack openings are the 540 major contribution to the toughening in the as-fabricated state. ${ }_{541}$ Considering the materials properties, there is a degradation ${ }_{542}$ from the as-fabricated to the embrittled material. This can be 543 seen in the fracture toughness values as well as in the appear-544 ance of the curves. The previous identification of the differ-545 ent active toughening mechanisms explains why the maximum ${ }_{546}$ load and the $\mathrm{K}_{\max }$ are one order of magnitude lower in the embrittled case than in the as-fabricated case. The composite properties of the as-fabricated and embrittled composite are mainly defined by the properties of the fibres which superpose ${ }_{548}$ all other mechanisms active in the material. In as-fabricated ${ }_{549}$ conditions the strength of the interlayer can be neglected as long as it debonds: The fracture strain of the fibres is much higher than the fracture strain of the matrix and the fibres will always debond, independently of the strength of the interlayer, which is according to theory [45]. This is in contrast to the embrittled case where the fibre properties are degraded and the interlayer debonding is crucial for crack bridging [46] and the rising load bearing capacity. All so far tested interlayers were tested with as-fabricated material $[9,47,48,49,50]$ but the further interlayer design needs to be optimized toward the embrittled, more crucial state.

A critical point in the shown evaluations is the validity of plane strain condition in the crack tip and the size criteria given in ASTM E399 and ASTM E1820. The plane strain condition seems to be valid in the embrittled samples as well as in the Jintegral testing as in both cases the crack opening is small compared to the specimen height. Due to the materials behaviour of $\mathrm{W}_{\mathrm{f}} / \mathrm{W}$ and the strict regulations of the ASTM E399 (curve shape, specimen size etc.) this standard should not be applied for further toughness evaluations.

\subsection{Comparison with tungsten and tungsten based materials}

Tungsten and tungsten based materials show at RT a brittle fracture with an instable crack propagation leading to a complete fracture of the specimens. Due to the brittle nature of W and W based materials at RT the use of the ASTM E399 is an appropriate method to calculate the fracture toughness $[18,51,52,33]$. This is in contrast to the here shown behaviour of $\mathrm{W}_{\mathrm{f}} / \mathrm{W}$ where stable crack propagation and a rising load bearing capacity after crack initiation was shown for as-fabricated and embrittled material at RT.

The crack initiation in the matrix of $\mathrm{W}_{\mathrm{f}} / \mathrm{W}$ starts at a value which is comparable to that of CVD-W with values of around 5 $\mathrm{MPa} \mathrm{m}^{1 / 2}$ [33]. As-fabricated $\mathrm{W}_{\mathrm{f}} / \mathrm{W}$ demonstrated a large contribution of the fibre ductility, the J-Integral should be applied for that case. The values calculated with the J-Integral are more than two times larger than the valid values calculated for polycrystalline tungsten at $400{ }^{\circ} \mathrm{C}$ [51].

Embrittled $\mathrm{W}_{\mathrm{f}} / \mathrm{W}$ has comparable fracture toughness values as observed in previous studies for $\mathrm{W}$ and $\mathrm{W}$ based materials $[18,51,52,33]$ and in addition stable crack growth.

As the load case of the material needs to be seen in combination with the active toughening mechanisms and the material behaviour, the pure fracture toughness values of $\mathrm{W}_{\mathrm{f}} / \mathrm{W}$ alone can hardly lead to material recommendation. In comparison to $\mathrm{W}, \mathrm{W}_{\mathrm{f}} / \mathrm{W}$ has the advantage that already at temperatures where other W materials are brittle, stable crack propagation and crack stopping is possible. In addition, local overloads and fabrication flaws which causes stress peaks do not lead to a complete failure. This allows design rules as used for metals such as defining critical crack length and maximum fatigue cycle limits.

\section{Summary and Conclusion}

The aim of this work was to investigate the fracture behaviour and to get a first estimation for the fracture toughness $\left(\mathrm{K}_{P}\right.$ and 


\section{References}

[1] ASTM E1820 - 09: Standard Test Method for Measurement of Fracture Toughness, 2013.

[2] E399 - 90: Standard Test Method for Plane-Strain Fracture Toughness of Metallic Materials.

[3] J.W. Coenen, S. Antusch, M. Aumann, W. Biel, J. Du, J. Engels, S. Heuer, A. Houben, T. Höschen, B. Jasper, F. Koch, J. Linke, A. Litnovsky, Y. Mao, R. Neu, G. Pintsuk, J. Riesch, M. Rasinski, J. Reiser, M. Rieth, A. Terra, B. Unterberg, Th. Weber, T. Wegener, J.-H. You, and Ch. Linsmeier. Materials for DEMO and reactor applications boundary conditions and new concepts. Physica Scripta, T167:014002, 2016.

[4] C. Gandhi and M.F. Ashby. Overview no. 5: Fracture-mechanism maps for materials which cleave: F.C.C., B.C.C. and H.C.P. metals and ceramics. Acta Metallurgica, 27(10):1565-1602, 1979.

[5] E. Lassner and W.-D. Schubert. Tungsten - Properties, Chemistry, Technology of the Element, Alloys, and Chemical Compound. Springer, 1999.
[6] W. Yih and C. Wang. Tungsten: Sources, Metallurgy, Properties, and Applications. Springer US, 1979.

[7] V. Barabash, G. Federici, M. Rödig, L. Snead, and C. Wu. Neutron irradiation effects on plasma facing materials. Journal of Nuclear Materials, 283-287:138-146, 2000.

[8] J.M. Steichen. Tensile properties of neutron irradiated TZM and tungsten. Journal of Nuclear Materials, 60:13-19, 1976.

[9] B. Jasper, S. Schönen, J. Du, T. Höschen, F. Koch, C. Linsmeier, R. Neu, J. Riesch, A. Terra, and J.W. Coenen. Behavior of tungsten fiberreinforced tungsten based on single fiber push-out study. Nuclear Materials and Energy, 9:416-421, 2016.

[10] Y. Mao, J.W. Coenen, J. Riesch, S. Sistla, J. Almannstötter, B. Jasper, A. Terra, T. Höschen, H. Gietl, M. Bram, J. Gonzalez-Julian, C. Linsmeier, and C. Bröckmann. Development and characterization of powder metallurgically produced discontinuous tungsten fiber reinforced tungsten composites. Physica Scripta, (T170):014005, 2017.

[11] R. Neu, J. Riesch, A.v. Müller, M. Balden, J.W. Coenen, H. Gietl, T. Höschen, M. Li, S. Wurster, and J.-H. You. Tungsten fibre-reinforced composites for advanced plasma facing components. Nuclear Materials and Energy, 12:1308-1313, 2016.

[12] J. Riesch, M. Aumann, J.W. Coenen, H. Gietl, G. Holzner, T. Höschen, P. Huber, M. Li, Ch. Linsmeier, and R. Neu. Chemically deposited tungsten fibre-reinforced tungsten - the way to a mock-up for divertor applications. Nuclear Materials and Energy, 9:75-83, 2016.

[13] J. Riesch, T. Höschen, Ch. Linsmeier, S. Wurster, and J.-H. You. Enhanced toughness and stable crack propagation in a novel tungsten fibrereinforced tungsten composite produced by chemical vapour infiltration. Physica Scripta, T159:014031, 2014.

[14] J.W. Coenen, Y. Mao, J. Almannstötter, A. Calvo, S. Sistla, H. Gietl, B. Jasper, J. Riesch, M. Rieth, G. Pintsuk, F. Klein, A. Litnovsky, A.v. Müller, T. Wegener, J.-H. You, C. Bröckmann, C. Garcia-Rosales, R. Neu, and C. Linsmeier. Advanced materials for a damage resilient divertor concept for DEMO: Powder-metallurgical tungsten-fibre reinforced tungsten. Fusion Engineering and Design, 124:964-968, 2016.

[15] A.G. Evans. Perspective on the development of high-toughness ceramics. Journal of American Ceramic Society, 73:187-206, 1990.

[16] R. Neu, J. Riesch, J.W. Coenen, J. Brinkmann, A. Calvo, S. Elgeti, C. Garcia-Rosales, H. Greuner, T. Höschen, G. Holzner, F. Klein, F. Koch, Ch. Linsmeier, A. Litnovsky, T. Wegener, S. Wurster, and J.-H. You. Advanced tungsten materials for plasma-facing components of DEMO and fusion power plants. Fusion Engineering and Design, 109-111: Part A:1046-1052, 2016.

[17] H. Gietl, J. Riesch, J.W. Coenen, T. Höschen, C. Linsmeier, and R. Neu. Tensile deformation behavior of tungsten fibre-reinforced tungsten composite specimens in as-fabricated state. Fusion Engineering and Design, 124:396-400, 2016.

[18] S. Wurster, B. Gludovatz, A. Hoffmann, and R. Pippan. Fracture behaviour of tungsten-vanadium and tungsten-tantalum alloys and composites. Journal of Nuclear Materials, 413:166-176, 2011.

[19] J.R. Rice. A path independent integral and the approximate analysis of strain concentration by notches and cracks. Journal of Applied Mechanics, 35(2):379-386, 1968.

[20] E. Gaganidze and J. Aktaa. Use of the failure assessment diagram to deduce ductile fracture toughness of the RAFM steel EUROFER97. International Journal of Pressure Vessels and Piping, 86:345-350, 2009.

[21] T.L. Anderson. Fracture Mechanics: Fundamentals and Applications. CRC Press, Taylor and Francis Group, 3. edition, 2005.

[22] P. Zhao, J. Riesch, T. Höschen, J. Almannstötter, M. Balden, J.W. Coenen, U. Himml, U. von Toussaint, and R. Neu. Microstructure, mechanical behavior and fracture of pure tungsten wires after different heat treatments. International Journal of Refractory Metals and Hard Materials, 68:2940, 2017.

[23] J. Du. A feasibility study of tungsten-fiber-reinforced tungsten composites with engineered interfaces. $\mathrm{PhD}$ thesis, Technische Universität München, 2010.

[24] H. Gietl, A.v. Müller, J. Riesch, J.W. Coenen, T. Höschen, Ph. Huber, M. Decius, D. Ewert, M. Milwich, and R. Neu. Textile techniques for tungsten fibre-reinforced composites production. Journal of Composite Materials, 52(28):3875-3884, 2018.

[25] J. Riesch, J. Almannstötter, J.W. Coenen, M. Fuhr, H. Gietl, Y. Han, T. Höschen, Ch. Linsmeier, N. Travitzky, and P. Zhao. Properties of 
drawn $\mathrm{W}$ wire used as high performance fibre in tungsten fibre-reinforced tungsten composite. IOP Conference Series: Materials Science and Engineering, 136:012043, 2016.

[26] J. Riesch, Y. Han, J. Almannstötter, J.W. Coenen, T. Höschen, B. Jasper, P. Zhao, Ch. Linsmeier, and R. Neu. Development of tungsten fibrereinforced tungsten composites towards their use in DEMO - potassium doped tungsten wire. Physica Scripta, T167:014006, 2016.

[27] Y. Mao, J.W. Coenen, J. Riesch, S. Sistla, J. Almanstötter, B. Jasper, A. Terra, T. Höschen, H. Gietl, Ch. Linsmeier, and C. Bröckmann. Influence of the interface strength on the mechanical properties of discontinuous tungsten fiber-reinforced tungsten composites produced by field assisted sintering technology. Composites Part A: Applied Science and Manufacturing, 107:342-353, 2018.

[28] A.v. Müller, M. Ilg, H. Gietl, T. Höschen, R. Neu, G. Pintsuk, J. Riesch, U. Siefken, and J.-H. You. The effects of heat treatment at temperatures of $1100{ }^{\circ} \mathrm{C}$ to $1300{ }^{\circ} \mathrm{C}$ on the tensile properties of high-strength drawn tungsten fibres. Nuclear Materials and Energy, 16:163-167, 2018.

[29] D.B. Marshall, B.N. Cox, and A.G. Evans. The mechanics of matrix cracking in brittle matrix fiber composites. Acta Metallurgica, 33:20132021, 1985.

[30] D. Gross and T. Seelig. Bruchmechanik - Mit einer Einführung in die Mikromechanik. Springer Verlag, 2016.

[31] A.G. Evans and D.B. Marshall. The mechanical behavior of ceramic matrix composites. Acta Metallurgica, 37:2567-2583, 1989

[32] S. Leber, J. Tavernelli, and D.D. White. Fracture modes in tungsten wire. Journal of the Less Common Metals, 48:119-133, 1976.

[33] J.D. Murphy, A. Giannattasio, Z. Yao, C.J.D. Hetherington, P.D. Nellist, and S.G. Roberts. The mechanical properties of tungsten grown by chemical vapour deposition. Journal of Nuclear Materials, 386-388:583-586, 2009.

[34] W.A. Bryant. The fundamentals of chemical vapour deposition. Journal of Materials Science, 12(7):1285-1306, 1977.

[35] H. Gietl, J.W. Riesch, J.W. Coenen, T. Höschen, and R. Neu. Production of tungsten-fibre reinforced tungsten composite by a novel continuous chemical vapour deposition process. Fusion Engineering and Design, 146:1426-1430, 2019

[36] W.A. Bryant. High-temperature strength stability of three forms of chemically vapor deposited tungsten. Journal of Vacuum Science and Technology, 11, 1974.

[37] T.M. Besmann, B.W. Sheldon, R.A. Lowden, and D.P. Stinton. Vaporphase fabrication and properties of continuous-filament ceramic composites. Science, 253(5024):1104-1109, 1991

[38] H.E. Deve and M.J. Maloney. On the toughening of intermetallics with ductile fibers: role of interfaces. Acta Metallurgica et Materialia, 39(10):2275-2284, 1991.

[39] H.E. Dève and S. Schmauder. Role of interface properties on the toughness of brittle matrix composites reinforced with ductile fibers. Journal of materials research, 7(11):3132-3138, 1992.

[40] J. Riesch, J.Y. Buffiere, T. Höschen, M. Scheel, Ch. Linsmeier, and J. H. You. Crack bridging in as-fabricated and embrittled tungsten single fibre-reinforced tungsten composites shown by a novel in-situ high energy synchrotron tomography bending test. Nuclear Materials and Energy, $15: 1-12,2018$

[41] A.G. Evans and F.W. Zok. The physics and mechanics of fibre-reinforced brittle matrix composites. Journal of Materials Science, 29:3857-3896, 1994

[42] D.R. Bloyer, R.O. Ritchie, and K.T. Venkateswara Rao. Fracture toughness and R-curve behavior of laminated brittle-matrix composites. Metallurgical and Materials Transactions A, 29(10):2483-2496, 1998.

[43] H. Gietl. Weiterentwicklung von wolframfaserverstärktem Wolframverbundwerkstoff für den Einsatz in der Fusion. $\mathrm{PhD}$ thesis, Technische Universität München, 2018.

[44] W. R. Holman and F. J. Huegel. Cvd tungsten and tungsten-rhenium alloys for structural applications. part ii. evaluation. In pp 427-58 of Proceedings of the Conference on Chemical Vapor Deposition of Refractory Metals, Alloys, and Compounds, Gatlinburg, Tennessee, September 1214, 1967. Schaffhauser, AC (ed.). Hinsd. Univ. of California, Livermore, 1968

[45] M.-Y. He and J.W. Hutchinson. Crack deflection at an interface between dissimilar elastic materials. International Journal of Solids and Structures, 25:1053-1067, 1989.
[46] J. B. Wachtman, W. R. Cannon, and Matthewson M. J. Mechanical Properties of Ceramics. 2. edition, 2009.

[47] H. Gietl, J. Riesch, J.W. Coenen, T. Höschen, M. Zielinski, and R. Neu. Comparison of interfacial shear strength of tungsten fibre-reinforced composites evaluated with different methods. In Preperation, 2019.

[48] J. Du, T. Höschen, M. Rasinski, S. Wurster, W. Grosinger, and J.-H. You. Feasibility study of a tungsten wire-reinforced tungsten matrix composite with $\mathrm{ZrOx}$ interfacial coatings. Composites Science and Technology, 70:1482-1489, 2010.

[49] J. Du, T. Höschen, M. Rasinski, and J.-H. You. Shear debonding behavior of a carbon-coated interface in a tungsten fiber-reinforced tungsten matrix composite. Journal of Nuclear Materials, 417:472-476, 2011.

[50] J. Du, T. Höschen, and J.-H. You. Thermal stability of the engineered interfaces in $\mathrm{W}_{f} / \mathrm{W}$ composites. Journal of Materials Science, 47:47064715, 2012.

[51] E. Gaganidze, D. Rupp, and J. Aktaa. Fracture behaviour of polycrystalline tungsten. Journal of Nuclear Materials, 446:240-245, 2014

[52] B. Gludovatz, S. Wurster, A. Hoffmann, and R. Pippan. Fracture toughness of polycrystalline tungsten alloys. International Journal of Refractory Metals and Hard Materials, 28(6):674-678, 2010. 